\title{
Changing trends in emergency coronary bypass surgery
}

\author{
Manjula Maganti, MSc, Stephanie J. Brister, MD, Terrence M. Yau, MSc, MD, Susan Collins, \\ Mitesh Badiwala, MD, and Vivek Rao, MD, PhD
}

Background: Patients undergoing emergency coronary artery bypass grafting represent a unique and high-risk population that remains challenging for cardiac surgeons. We examined the changing trends in patients undergoing emergency bypass grafting over the past 20 years.

\begin{abstract}
Methods: We conducted a retrospective review of our database between 1990 and 2009 and patients were divided into 2 groups based on year of operation: 1990-1999, $\mathrm{n}=393$; 2000-2009, $\mathrm{n}=184$. The primary outcomes of interest for this study are operative mortality and incidence of low cardiac output syndrome.
\end{abstract}

Results: The percentage of patients undergoing emergency coronary bypass grafting has decreased from $2.7 \%$ to $1.7 \%$ over time. The percentage of patients with dyslipidemia, hypertension, triple vessel disease, peripheral vascular disease, and left main disease increased over time $(P<.05)$. Operative mortality remained at $8.1 \%$ in both year groups. Preoperative hypertension, congestive heart failure, left ventricular ejection fraction less than $20 \%$, and previous cardiac surgery independently predicted operative mortality by logistic regression analysis. Low cardiac output syndrome developed in $25 \%$ of the patient population undergoing emergency bypass grafting. The independent predictors of low cardiac output syndrome were small body surface area, congestive heart failure, shock, myocardial infarction, earlier decade (1990-1999) and increased age.

Conclusions: Despite a changing preoperative risk profile, the operative mortality of emergency coronary artery bypass grafting has remained stable over the years. However, mortality remains significantly above the observed mortality in elective bypass grafting. Continued improvements in the management of heart failure and the care of the elderly will likely result in reduced risks of emergency coronary artery bypass grafting. (J Thorac Cardiovasc Surg 2011;142:816-22)

Patients undergoing emergency coronary artery bypass grafting $(\mathrm{CABG})$ represent a unique and high-risk population that remains challenging for cardiac surgeons. Since the introduction of percutaneous coronary intervention (PCI), volumes of emergency CABG have started to decrease as many programs implement primary PCI for the treatment of acute coronary syndromes. It is not clear how this paradigm shift has altered the risk profile of patients referred for emergency CABG. It is probable that perioperative morbidity and mortality are higher in patients undergoing emergency CABG after failed PCI. We examined the changing trends in the preoperative risk profiles, postoperative outcomes, and hospital resource use in patients undergoing emergency CABG over the past 20 years.

\section{METHODS}

The study population included all patients who underwent emergency CABG between 1990 and December 2009 at the Toronto General Hospital.

From the Division of Cardiovascular Surgery, PeterMunk Cardiac Center, University Health Network, University of Toronto, Toronto, Ontario, Canada.

Disclosures: Authors have nothing to disclose with regard to commercial support.

Received for publication June 23, 2010; revisions received Dec 9, 2010; accepted for publication Jan 10, 2011; available ahead of print Feb 21, 2011.

Address for reprints: Vivek Rao, MD, PhD, Alfredo and Teresa DeGasperis Chair in

Heart Failure Surgery, Toronto General Hospital, 4N-464, 200 Elizabeth St,

Toronto, Ontario M5G 2C4, Canada (E-mail: vivek.rao@uhn.on.ca).

$0022-5223 / \$ 36.00$

Copyright (c) 2011 by The American Association for Thoracic Surgery doi:10.1016/j.jtcvs.2011.01.021
Emergency CABG is defined as surgery within 12 hours from the event resulting in hospitalization. The reasons for emergency surgery are either anatomic (critical left main stenosis) or unstable symptoms after catheterization. Patients who have recurrent angina after catheterization are usually admitted to the cardiac care unit and referred for urgent surgery (within 48 hours). The present analysis is restricted to emergency interventions (within 12 hours of an event) and thus includes patients with ostial left main lesions, a PCI complication (eg, coronary dissection or perforation, acute stent thrombosis), or unstable symptoms (hypotension, dynamic electrocardiographic changes, or arrhythmias). Unfortunately, our database does not capture the exact reason for emergency surgery apart from capturing preoperative PCI. All patient data were entered prospectively into an institutional database by a trained database management group. Preoperative, intraoperative, and postoperative data were collected on standard variables. The details of this database have been published previously. ${ }^{1-3}$

To examine the effect of time, we divided patients into 2 groups on the basis of year of operation: 1990-1999 and 2000-2009. The preoperative risk profile, intraoperative data, and postoperative outcomes of the study population are compared with those of patients receiving nonemergency surgery in each decade. Nonemergency operations include all the elective, same-day hospitalization, and urgent procedures.

The primary outcomes of interest for this study are operative mortality and incidence of low cardiac output syndrome (LCOS). Operative mortality is defined as any postoperative death occurring within the index hospital admission or within 30 days of surgery. LCOS was diagnosed if the patient required an intra-aortic balloon pump to be weaned from cardiopulmonary bypass or in the intensive care unit (ICU) because of hemodynamic compromise. LCOS was also diagnosed if the patient required inotropic medication (dopamine, dobutamine, milnirone, or epinephrine) to maintain the systolic blood pressure of $90 \mathrm{~mm} \mathrm{Hg}$ and the cardiac output $2.2 \mathrm{~L} \cdot \mathrm{min}^{-1} \cdot \mathrm{m}^{-2}$ for 30 minutes in the ICU after correction of all of the electrolyte and blood gas abnormalities and after adjusting the preload to its optimal value. Afterload reduction was also attempted when possible. 

Abbreviations and Acronyms
$\mathrm{CABG}=$ coronary artery bypass grafting
$\mathrm{CHF}=$ congestive heart failure
ICU = intensive care unit
LCOS $=$ low cardiac output syndrome
LVEF $=$ left ventricular ejection fraction
MI = myocardial infarction
PCI = percutaneous coronary intervention
STS $=$ Society of Thoracic Surgeons

Patients who received $4 \mu \mathrm{g} / \mathrm{kg}$ of dopamine to increase renal perfusion were not considered to have LCOS. Patients who received vasoconstricting medications because of a high cardiac output $\left(2.5 \mathrm{~L} \cdot \mathrm{min}^{-1} \cdot \mathrm{m}^{-2}\right)$ and low peripheral resistance were also not considered to have LCOS. In patients who received an intra-aortic balloon pump before surgery, LCOS was determined if, in addition to balloon pump support, they required significant postoperative inotropic support as described earlier.

Hospital resource use is defined by 3 different variables: length of time supported by mechanical ventilation before postoperative tracheal extubation, duration of stay in the ICU, and postoperative length of stay.

\section{STATISTICAL ANALYSIS}

All statistical analyses were conducted with SAS 9.1 software (SAS Institute, Inc, Cary, NC). ${ }^{4}$ Categorical variables were analyzed using the $\chi^{2}$ test and are expressed as percentages. Continuous variables were analyzed by the Student $t$ test or Wilcoxon rank sum test and are reported as mean \pm standard deviation or median where appropriate. Multivariable logistic regression techniques were used to determine independent predictors and to calculate factoradjusted odds ratios of operative mortality and LCOS. Model discrimination was evaluated by the area under receiver-operator characteristic curve and model calibration was assessed with the Hosmer-Lemeshow goodness-of-fit statistic. $^{5-7}$

\section{RESULTS}

To examine outcomes over time, we divided patients into 2 groups on the basis of year of operation (1990-1999 and 2000-2009). The percentage of patients having emergency CABG in the overall CABG population was $2.7 \%$ in 1990 1999 and $1.7 \%$ in 2000-2009. The percentage of patients who underwent emergency CABG gradually decreased over the years as shown in Figure 1.

The changing preoperative risk profile of patients in the 2 decades of study is shown in Table 1. Patients who received emergency surgery are compared with those receiving nonemergency surgery and the comparisons are stratified by decade. Also, comparisons are made between patients receiving emergency surgery in each decade, and the corresponding $P$ value is provided in the last column of the table.
In the first decade, the mean age of the patients ranged between 62 and 63 years. Patients in the emergency group were $31 \%$ female and had a higher incidence of poor left ventricular ejection fraction (LVEF), acute coronary insufficiency, myocardial infarction (MI), congestive heart failure (CHF), renal failure, shock, syncope, and left main disease. Those requiring emergency surgery also had a higher prevalence of previous angioplasty and CABG. Patients in the nonemergency group were $20 \%$ female and had a higher incidence of dyslipidemia and triple vessel disease.

In the second decade of study, the mean age of patients ranged from 64 to 65 years. Patients in the emergency group were $35 \%$ female and had higher incidence of poor LVEF, acute coronary insufficiency, CHF, MI, shock, and left main disease. They also had a higher prevalence of previous angioplasty, but not previous CABG. Patients in the nonemergency group were $21 \%$ female and had a higher incidence of dyslipidemia, diabetes, and triple vessel disease.

The mean age of patients in the emergency group increased from 62 years in the first decade of the study to 64 years in the second decade. Similarly, the prevalence of triple vessel disease, left main disease, peripheral vascular disease, and percentage of patients with dyslipidemia and hypertension increased from the earlier to the recent decade. Approximately $60 \%$ of patients had a family history of heart disease in the earlier decade and only $40 \%$ had a family history between 2000 and 2009. Over the 2 time groups, no significant differences were observed in preoperative diabetes, CHF, shock, MI, stroke, or LVEF. The percentage of patients with previous angioplasty and previous thrombolysis decreased over the years. Similarly, the prevalence of chronic obstructive pulmonary disease and renal failure also decreased. The proportion of women who underwent $\mathrm{CABG}$ was similar over the 2 decades, as shown in Table 1.

Three hundred seventy-seven $(65 \%)$ patients in our emergency population had no prior PCI and $200(35 \%)$ had prior PCI. Among the 200 patients, 165 had PCI less than 30 days before surgery and the remaining 35 patients had PCI at various times before CABG ranging from 1 to 144 months. The percentage of previous PCI in patients undergoing emergency $\mathrm{CABG}$ was $38 \%$ and $28 \%$, respectively, over the 2 year groups. However, the percentage of CABG patients undergoing emergency surgery after failed PCI was $32 \%$ in the first cohort and $21 \%$ in the second cohort.

Intraoperative details for the study population are listed in Table 2. Duration of cardiopulmonary bypass, crossclamp time, and use of the left internal thoracic artery are higher in the nonemergency population in both decades. In the emergency population, use of the left and right internal thoracic arteries did not change significantly over the years. The total number of grafts per patient was similar in the 2 time periods. The average crossclamp time 


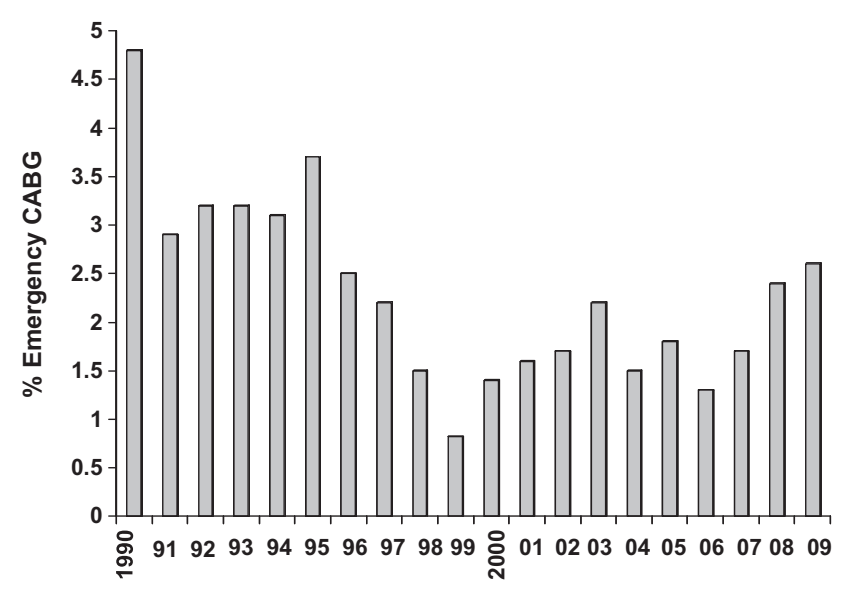

FIGURE 1. Prevalence of Emergent CABG.

increased slightly in the recent decade; however, the mean duration of cardiopulmonary bypass time did not change over time. Off-pump surgical revascularization was introduced in the more recent decade but accounted for only $10 \%$ of the population.

Hospital resource use in terms of hours on ventilator, ICU length of stay, and hospital length of stay were lower in the nonemergency population than in the emergency population (Table 3) In the emergency population, mean ventilation time and ICU stay increased over time. However, the difference was not statistically significant. In both cohorts the data on ventilator hours and ICU stay are skewed to the right, more highly in the second cohort than in the first cohort. Median time on ventilator was 24 and 16 hours, respectively, and median ICU length of stay was 49 and 61 hours, respectively. Average hospital stay decreased slightly from 11.4 days in the first cohort to 11 days in the second cohort. Median postoperative length of stay was 8 and 7 days, respectively.

The distribution of postoperative outcomes is listed in Table 3. The nonemergency population had lower use of inotropes and lower incidence of postoperative MI, renal failure, and pulmonary complications in both decades of study. However, incidence of sternal wound infection was lower in the first decade, and incidence of postoperative stroke and sepsis was lower in the second decade. In the emergency population, use of inotropes has increased over the years. Pulmonary and septic complications were also on the rise in the recent cohort as was the incidence of postoperative stroke.

The overall operative mortality in the emergency population was $8.1 \%$, whereas the overall operative mortality in the nonemergency population was $1.6 \%$. Operative mortality was similar in the emergency population in both decades at $8.1 \%$. However, operative mortality of our nonemergency population has gone down significantly from $1.9 \%$ in $1990-1999$ to $1.1 \%$ in $2000-2009$. The cause of death was not specified in 12 patients, while 20 patients died of acute cardiogenic shock secondary to postoperative LCOS. An additional 6 patients died of overwhelming sepsis and 6 patients died of progressive multiorgan failure. One patient positive for heparin-induced thrombocytopenia died of intractable bleeding owing to the use of ancrod for cardiopulmonary bypass.

Multivariable logistic regression analysis of the $577 \mathrm{pa}-$ tients in the emergency group who underwent operation during the period of the study showed that hypertension, CHF, LVEF less than $20 \%$, and previous heart surgery independently identified mortality (Table 4). The univariate operative mortality in patients with or without the aforementioned risk factors is as follows: hypertension, $11.4 \%$ versus $3.7 \% ; P<.01 ; \mathrm{CHF}, 18.9 \%$ versus $4.3 \% ; P<.0001 ; \mathrm{LVEF}$ less than $20 \%: 29.1 \%$ versus $5.8 \% ; P<.0001$; previous surgery: $18.2 \%$ versus $7.3 \% ; P=.01$. The model for logistic regression has a receiver-operator characteristic of 0.78 and a Hosmer-Lemeshow goodness-of-fit probability value of 0.89 , indicating excellent model discrimination and calibration.

The overall incidence of LCOS was 5.3\% in the nonemergency population: $6.9 \%$ in $1990-1999$ versus $3.1 \%$ in 2000-2009. However, $25 \%$ of the patient population undergoing emergency CABG had LCOS; $26.5 \%$ in 1990 1999 versus $18.6 \%$ in $2000-2009$. Operative mortality in the patients with emergency surgery who had LCOS was $25.4 \%$ compared with $2.5 \%$ in patients who did not have LCOS. The logistic regression model for LCOS identified smaller body surface area, CHF, shock, MI, previous decade, and increased age as significant independent variables that influence LCOS. The corresponding odds ratios and $P$ values for the significant variables associated with LCOS are provided in Table 5. The model has an area under the curve of 0.74 and Hosmer-Lemeshow goodness-of-fit $P$ value of .67.

\section{DISCUSSION}

Timing of CABG has been widely reported as one of the most important predictors of in-hospital mortality. ${ }^{8-10} \mathrm{~A}$ previous report published by our group ${ }^{11}$ reviewed 18,000 patients and identified emergency CABG as one of the most important predictors of in-hospital mortality. Emergency CABG came out as a predictor in all 3 year groups we studied and the odds ratios associated with in-hospital mortality increased from 4 to 19 over the years. As an active teaching hospital that performs a significantly high volume of CABG operations each year, we were interested to document trends in preoperative risk profile, postoperative outcomes, and predictors of in-hospital mortality and LCOS in patients undergoing emergency CABG.

The percentage of patients undergoing emergency CABG decreased over the years and varied between $4.8 \%$ in 1990 to $2.6 \%$ in 2009 . The decline in numbers over the 
TABLE 1. Distribution of preoperative variables

\begin{tabular}{|c|c|c|c|c|c|c|c|}
\hline $\begin{array}{c}\text { Variable } N(\%) \text { or } \\
\text { mean } \pm \text { SD }\end{array}$ & $\begin{array}{c}\text { 1990-1999 } \\
\text { (emerg) }\end{array}$ & $\begin{array}{l}\text { 1990-1999 } \\
\text { (nonemerg) }\end{array}$ & $P$ value & $\begin{array}{c}\text { 2000-2009 } \\
\text { emerg }\end{array}$ & $\begin{array}{l}\text { 2000-2009 } \\
\text { (nonemerg) }\end{array}$ & $\begin{array}{c}P \\
\text { value }\end{array}$ & $\begin{array}{l}P \text { value comparing } \\
\text { emerg populations }\end{array}$ \\
\hline No. of patients & 393 & 14,374 & & 184 & 10,395 & & - \\
\hline Age (y) & $62 \pm 11$ & $63 \pm 10$ & .15 & $64 \pm 12$ & $65 \pm 10$ & .18 & .03 \\
\hline Body surface area $\left(\mathrm{m}^{2}\right)$ & $1.88 \pm 0.2$ & $1.92 \pm 0.2$ & .002 & $1.87 \pm 0.2$ & $1.92 \pm 0.2$ & .002 & .54 \\
\hline Female & $123(31.3)$ & $3012(21)$ & $<.001$ & $64(34.8)$ & $2153(20.7)$ & $<.001$ & .4 \\
\hline Hypertension & $209(54.2)$ & $7482(52.1)$ & .4 & $116(63)$ & $7158(68.9)$ & .09 & .04 \\
\hline Dyslipidemia & $195(52.1)$ & $8566(60.2)$ & .002 & $135(74.2)$ & $8904(85.8)$ & $<.001$ & $<.0001$ \\
\hline Diabetes mellitus & $99(25.5)$ & $3729(26)$ & .84 & $42(22.8)$ & $3698(35.6)$ & $<.001$ & .48 \\
\hline Family history of heart disease & $217(58)$ & $9213(65)$ & .009 & $78(42.8)$ & $6227(60.3)$ & $<.001$ & $<.001$ \\
\hline LVEF & & & $<.001$ & & & $<.001$ & .001 \\
\hline$>60 \%$ & $100(25.6)$ & 4537 (31.6) & & $76(41.8)$ & $4719(45.4)$ & & \\
\hline $40 \%-60 \%$ & $163(41.8)$ & $6441(45)$ & & $57(31.3)$ & $3687(35.5)$ & & \\
\hline $20 \%-39 \%$ & $88(22.6)$ & $2978(20.8)$ & & $33(18.1)$ & $1780(17.1)$ & & \\
\hline$<0 \%$ & $39(10.0)$ & $397(2.8)$ & & $16(8.8)$ & $198(1.9)$ & & \\
\hline NYHA class & & & $<.001$ & & & $<.001$ & .46 \\
\hline I or II or III & $20(5.1)$ & $7241(50.4)$ & & $12(6.6)$ & $5455(53.8)$ & & \\
\hline IV & $373(94.9)$ & $7133(49.6)$ & & $170(93.4)$ & $4688(46.2)$ & & \\
\hline Preoperative location & & & $<.001$ & & & $<.001$ & .23 \\
\hline Coronary care unit & $250(65.3)$ & $1576(11.1)$ & & $133(72.3)$ & $964(9.3)$ & & \\
\hline Catheterization laboratory & $106(27.7)$ & 7 (0.05) & & $42(22.8)$ & $1(0.01)$ & & \\
\hline Other & $27(7.1)$ & $12657(88.9)$ & & $9(4.9)$ & 9427 (90.7) & & \\
\hline Triple vessel disease & $221(56.2)$ & $10689(74.4)$ & $<.001$ & $129(70.1)$ & $8427(81.1)$ & $<.001$ & .001 \\
\hline No. of diseased vessels & $2.4 \pm 0.72$ & $2.7 \pm 0.5$ & $<.001$ & $2.6 \pm 0.65$ & $2.8 \pm 0.46$ & $<.001$ & .003 \\
\hline Angina & & & $<.001$ & & & $<.001$ & .35 \\
\hline Stable or crescendo & $72(18.5)$ & $9970(69.4)$ & & $40(21.9)$ & $7986(76.9)$ & & \\
\hline Acute coronary insufficiency & $317(81.5)$ & $4392(30.6)$ & & $143(78.1)$ & $2399(23.1)$ & & \\
\hline $\mathrm{CHF}$ & 109 (27.9) & $1163(8.1)$ & $<.001$ & $44(23.9)$ & $1023(9.8)$ & $<.001$ & .32 \\
\hline Atrial fibrillation & $3(0.76)$ & $185(1.3)$ & .36 & $2(1.1)$ & $247(2.4)$ & .25 & .65 \\
\hline Peripheral vascular disease & $60(15.6)$ & $2099(14.7)$ & .59 & $43(23.4)$ & $2016(19.4)$ & .18 & .03 \\
\hline COPD & $50(12.7)$ & $1768(12.3)$ & .8 & $3(1.6)$ & $454(4.4)$ & .07 & $<.0001$ \\
\hline Myocardial infarction & $218(55.9)$ & $2498(17.4)$ & $<.001$ & $104(56.5)$ & $2281(21.9)$ & $<.001$ & .88 \\
\hline Stroke & $36(9.3)$ & $1219(8.5)$ & .6 & $14(7.6)$ & $935(9.0)$ & .5 & .5 \\
\hline Renal failure & $24(6.1)$ & $419(2.9)$ & $<.001$ & 0 & $142(1.4)$ & .11 & $<.001$ \\
\hline Shock & $81(20.7)$ & $96(0.7)$ & $<.001$ & $37(20.1)$ & $93(0.89)$ & $<.001$ & .86 \\
\hline Syncope & $17(4.3)$ & $252(1.8)$ & $<.001$ & 7 (3.8) & $223(2.2)$ & .12 & .77 \\
\hline Left main disease & $101(25.7)$ & $2598(18.1)$ & $<.001$ & $123(66.9)$ & $2987(28.7)$ & $<.001$ & $<.0001$ \\
\hline Previous angioplasty & $148(37.7)$ & $1281(8.9)$ & $<.001$ & $52(28.3)$ & $983(9.5)$ & $<.001$ & .03 \\
\hline Previous thrombolysis & $68(18.3)$ & $1327(9.5)$ & $<.001$ & $17(9.2)$ & $550(5.3)$ & .02 & .005 \\
\hline Previous CABG & $35(8.9)$ & $849(5.9)$ & .01 & $6(3.3)$ & $313(3.0)$ & .8 & .01 \\
\hline Previous heart surgery & $35(8.9)$ & $883(6.1)$ & .02 & $9(4.9)$ & $338(3.3)$ & .2 & .09 \\
\hline
\end{tabular}

$S D$, Standard devation; $L V E F$, left ventricular ejection fraction; $N Y H A$, New York Heart Association; $C H F$, congestive heart failure; COPD, chronic obstructive pulmonary disease; $C A B G$, coronary artery bypass grafting.

years is attributed in great part to the emergence of PCI. A multitude of information is available on outcomes of patients undergoing emergency CABG after failed PCI. Multivariable predictors of hospital mortality in the failed PCI group are slightly different from those observed in our patient population. ${ }^{12,13}$ Perhaps this may be due to differences in patient risk profile presenting to surgery after failed PCI. Boylan and colleagues ${ }^{14}$ suggest that death from CABG after failed PCI is related more to the incidence of cardiogenic shock and hemodynamic instability after unsuccessful PCI than it is to the risk factors present before PCI. However, information on patients undergoing emer- gency CABG without prior PCI is sparse to the best of our knowledge, especially in the most recent era when primary PCI for acute coronary syndromes is the standard of care. Presumably, CABG in these patients was indicated owing to critical coronary anatomy not suitable for PCI. Previous reports from our group ${ }^{1,11}$ have suggested that operative risk for urgent surgery is related more to symptom status than to anatomic criteria.

As anticipated, the risk profile of patients has constantly changed over the years. The mean age increased from 62 to 64 years. Similarly, the prevalence of triple vessel disease, left main disease, peripheral vascular disease, dyslipidemia, 
TABLE 2. Distribution of intraoperative variables

\begin{tabular}{|c|c|c|c|c|c|c|c|}
\hline $\begin{array}{c}\text { Variable } \\
\mathbf{N}(\%) \text { or mean } \pm \text { SD }\end{array}$ & $\begin{array}{c}\text { 1990-1999 } \\
\text { (emerg) }\end{array}$ & $\begin{array}{c}\text { 1990-1999 } \\
\text { (nonemerg) }\end{array}$ & $P$ value & $\begin{array}{c}\text { 2000-2009 } \\
\text { (emerg) }\end{array}$ & $\begin{array}{c}\text { 2000-2009 } \\
\text { (nonemerg) }\end{array}$ & $P$ value & $\begin{array}{l}P \text { value comparing } \\
\text { emerg populations }\end{array}$ \\
\hline No of patients & 393 & 14,374 & & 184 & 10,395 & & \\
\hline Duration of CPB (min) & $82 \pm 32$ & $86 \pm 28$ & .02 & $83 \pm 27$ & $90.5 \pm 25$ & $<.001$ & .99 \\
\hline Duration of XCL (min) & $54 \pm 19$ & $62 \pm 19$ & $<.001$ & $57 \pm 20$ & $68.8 \pm 21$ & $<.001$ & .04 \\
\hline Use of LITA & $221(56.2)$ & $12,559(87.4)$ & $<.001$ & $107(58.2)$ & $9396(90.4)$ & $<.001$ & 6 \\
\hline Use of RITA & $8(2.0)$ & $412(2.9)$ & .3 & $1(0.54)$ & $825(7.9)$ & $<.001$ & .2 \\
\hline Off-pump surgery & - & $254(1.8)$ & .03 & $19(10.3)$ & $766(7.4)$ & .13 & - \\
\hline No. of arteries bypassed & $3.2 \pm 10$ & $3.6 \pm 0.91$ & $<.001$ & $3.1 \pm 0.9$ & $3.5 \pm 0.89$ & $<.001$ & .9 \\
\hline
\end{tabular}

$S D$, Standard deviation; $C P B$, cardiopulmonary bypass; $X C L$, aortic crossclamp; LITA, left internal thoracic artery; RITA, right internal thoracic artery.

and hypertension gradually increased from the earliest to the most recent cohort. This is in agreement with previously published reports. ${ }^{8-11,15}$ However, the proportion of women who underwent emergency $\mathrm{CABG}$ was similar over the 2 year groups.

In-hospital mortality of our emergency patient population has remained constant at $8.1 \%$ in both year groups. We have a total of 47 deaths among 577 patients. Our numbers are in accordance with the reported operative mortality of emergency patients in the Society of Thoracic Surgeons (STS) database. Recently, Shahian and coworkers ${ }^{13}$ published cardiac surgery risk models using 774,881 CABG patients from the STS database, and among them 34,513 patients underwent emergency CABG. The operative mortality in this cohort was also $8.1 \%$. Operative mortality has not changed over time despite the changing preoperative risk profile of patients. However, the operative mortality of our nonemergency patient population has gone down significantly from $1.9 \%$ in the earlier era to $1.1 \%$ in the recent era.
Operative mortality in our emergency female population was slightly higher $(10.2 \%)$ than that of the male population $(7.2 \%)$, but the difference did not achieve statistical significance. This finding is consistent with previously reported data from the STS database that operative mortality is not significantly different between male and female genders in high-risk patients undergoing CABG. ${ }^{16}$

The independent predictors of operative mortality in this group of 577 patients are hypertension, previous CABG, LVEF less than 20\%, and CHF. These variables are similar to some of the variables identified by our group in an elective $\mathrm{CABG}$ population. $^{11}$

\section{Hypertension}

Approximately $56 \%$ of the population had preoperative hypertension, and the operative mortality in that group was $11.4 \%$ as opposed to $3.7 \%$ in patients without hypertension. The percentage of patients with hypertension increased from the first to the second decade, whereas the

TABLE 3. Distribution of postoperative outcomes

\begin{tabular}{|c|c|c|c|c|c|c|c|}
\hline $\begin{array}{c}\text { Variable } \\
\mathbf{N}(\%) \text { or mean } \pm \mathrm{SD}\end{array}$ & $\begin{array}{c}\text { 1990-1999 } \\
\text { (emerg) }\end{array}$ & $\begin{array}{c}\text { 1990-1999 } \\
\text { (nonemerg) }\end{array}$ & $\begin{array}{c}P \\
\text { value }\end{array}$ & $\begin{array}{c}\text { 2000-2009 } \\
\text { (emerg) }\end{array}$ & $\begin{array}{c}\text { 2000-2009 } \\
\text { (nonemerg) }\end{array}$ & $\begin{array}{c}P \\
\text { value }\end{array}$ & $\begin{array}{l}P \text { value comparing } \\
\text { emerg populations }\end{array}$ \\
\hline No. of patients & 393 & 14374 & & 184 & 10,395 & & \\
\hline Mortality & $32(8.14)$ & 275 (1.9) & $<.001$ & $15(8.15)$ & $113(1.1)$ & $<.001$ & .99 \\
\hline $\mathrm{LCOS}$ & $104(26.5)$ & $986(6.9)$ & $<.001$ & $34(18.6)$ & $325(3.1)$ & $<.001$ & .04 \\
\hline IABP & & & $<.001$ & & & $<.001$ & .15 \\
\hline None & $146(37.1)$ & $13435(93.5)$ & & $71(38.6)$ & 9935 (95.6) & & \\
\hline Preoperative & $218(55.5)$ & $296(2.1)$ & & $107(58.2)$ & $220(2.1)$ & & \\
\hline Postoperative & $29(7.4)$ & $642(4.5)$ & & $6(3.2)$ & $240(2.3)$ & & \\
\hline Use of inotropes & $224(57)$ & $4366(30.4)$ & $<.001$ & $128(70)$ & $3975(38.3)$ & $<.001$ & $<.01$ \\
\hline Myocardial infarction & $19(4.8)$ & $394(2.8)$ & .01 & $9(4.9)$ & $258(2.5)$ & .04 & .9 \\
\hline Stroke & $3(0.76)$ & $210(1.5)$ & .25 & $7(3.8)$ & $98(0.94)$ & $<.001$ & $<.01$ \\
\hline Renal failure & $8(2.0)$ & $126(0.88)$ & .02 & $10(5.5)$ & $101(0.99)$ & $<.001$ & .03 \\
\hline Sternal wound infection & $19(4.8)$ & $377(2.6)$ & .007 & $4(2.2)$ & 206 (1.9) & .8 & .1 \\
\hline Sepsis & $5(1.3)$ & $96(0.7)$ & .2 & $10(5.4)$ & $141(1.4)$ & $<.001$ & $<.01$ \\
\hline Reoperation for bleeding & $8(2.0)$ & $240(1.7)$ & 6 & $8(4.4)$ & $272(2.6)$ & .15 & .1 \\
\hline Pulmonary complications & $44(11.2)$ & $1248(8.7)$ & .08 & $43(23.4)$ & $854(8.2)$ & $<.001$ & $<.001$ \\
\hline Insertion of pacemaker & $4(10)$ & $105(0.73)$ & .5 & $11(6)$ & $159(1.5)$ & $<.001$ & $<.001$ \\
\hline Hours on ventilator & $36.8 \pm 60.3$ & $19.1 \pm 56.5$ & $<.001$ & $62 \pm 137$ & $16.1 \pm 55.7$ & $<.001$ & .7 \\
\hline ICU length of stay (h) & $80.2 \pm 85$ & $48.5 \pm 86$ & $<.001$ & $112 \pm 171$ & $51.5 \pm 109$ & $<.001$ & .7 \\
\hline Hospital length of stay (d) & $11.4 \pm 12.3$ & $8.8 \pm 9.1$ & $<.001$ & $11 \pm 12.5$ & $7.9 \pm 9.0$ & $<.001$ & .04 \\
\hline
\end{tabular}

$S D$, Standard deviation; $L C O S$, low cardiac output syndrome; IABP, intra-aortic balloon pump; ICU, intensive care unit. 
TABLE 4. Multivariable predictors of operative mortality

\begin{tabular}{lcccc}
\hline \multicolumn{1}{c}{ Variable } & $\begin{array}{c}\text { Regression } \\
\text { coefficient } \pm \text { SE }\end{array}$ & $\begin{array}{c}\text { Odds } \\
\text { ratio }\end{array}$ & $\mathbf{9 5 \% \text { CI }}$ & $\begin{array}{c}\boldsymbol{P} \\
\text { value }\end{array}$ \\
\hline Hypertension & $1.3 \pm 0.42$ & 3.5 & $1.6-8.0$ & $<.01$ \\
Congestive heart failure & $1.1 \pm 0.47$ & 3.3 & $1.5-6.9$ & $<.01$ \\
LVEF $<20 \%$ & $1.2 \pm 0.42$ & 3.1 & $1.4-7.2$ & $<.01$ \\
Previous heart surgery & $1.2 \pm 0.38$ & 3.0 & $1.2-7.7$ & .02 \\
\hline
\end{tabular}

$S E$, Standard error; $C I$, confidence interval; $L V E F$, left ventricular ejection fraction.

operative mortality decreased slightly from $12 \%$ to $10.3 \%$. We had previously identified hypertension as a risk factor in our elective CABG population. ${ }^{11}$ We hypothesize that hypertension results in myocardial hypertrophy and thus may lead to inadequate perioperative myocardial protection. Second, hypertension is associated with diastolic dysfunction, and in those patients undergoing emergency surgery for acute myocardial ischemia, the combination of systolic and diastolic dysfunction may prove lethal.

\section{Reoperative CABG}

Seven percent of the patient population underwent previous $\mathrm{CABG}$, and the operative mortality in this group was $18.2 \%$ compared with $7.3 \%$ in patients undergoing firsttime surgery. The number of patients undergoing reoperation declined over the years from $8.9 \%$ in the first cohort to $3.3 \%$ in the last cohort. Operative mortality in emergency redo $\mathrm{CABG}$ also has a decreasing trend over the year groups: $20 \%$ versus $16.6 \%$. A similar trend was observed in our elective population over the years as reported previously. ${ }^{11}$ The decline in reoperations is also likely due to a more aggressive PCI strategy in patients with recurrent coronary artery disease after surgical revascularization.

Twenty-nine percent of the patients underwent unsuccessful PCI. Although statistically not significant, the operative mortality in the failed PCI group is slightly lower than in patients who did not have prior PCI $(6.1 \%$ vs $8.9 \%)$. This may be attributed to the fact that patients who had previous PCI are younger (mean age: 58 vs 64 years, respectively; $P<.01)$ and had fewer comorbidities than patients who did not have any intervention. Our operative mortality outcomes in the failed PCI group are on par with outcomes

TABLE 5. Multivariable predictors of low cardiac output syndrome

\begin{tabular}{lclcr}
\hline \multicolumn{1}{c}{ Variable } & $\begin{array}{c}\text { Regression } \\
\text { coefficient } \pm \text { SE }\end{array}$ & $\begin{array}{c}\text { Odds } \\
\text { ratio }\end{array}$ & $\mathbf{9 5 \%}$ CI & $\begin{array}{c}\boldsymbol{P} \\
\text { value }\end{array}$ \\
\hline Smaller BSA & $-1.5 \pm 0.54$ & 4.5 & $1.6-12.9$ & $<.01$ \\
CHF & $0.79 \pm 0.26$ & 2.2 & $1.3-3.7$ & $<.01$ \\
Shock & $0.69 \pm 0.28$ & 1.99 & $1.2-3.4$ & .01 \\
Preop MI & $0.68 \pm 0.24$ & 1.98 & $1.2-3.2$ & $<.01$ \\
1990-1999 vs & $0.51 \pm 0.24$ & 1.7 & $1.04-2.7$ & .03 \\
$\quad$ & & & & \\
2000-2009 & $0.02 \pm 0.01$ & 1.24 & $1.01-1.52$ & .04 \\
\hline
\end{tabular}

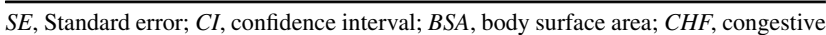
heart failure; $M I$, myocardial infarction. published by Haan and associates ${ }^{12}$ from the STS database in patients undergoing emergency CABG after failed PCI. Fourteen of 577 patients underwent both PCI and previous CABG and 4 died among them.

\section{LVEF}

Poor LVEF was identified as one of the most important risk factors of operative mortality in CABG patients as seen in various published reports. ${ }^{8,10,13}$ Patients with poor LVEF represented $9.5 \%$ of our patient population, and the operative mortality in this group was $29.1 \%$. The number of patients with poor LVEF slightly decreased over the years from $10 \%$ to $8.8 \%$. Similarly, operative mortality also slightly decreased from $31 \%$ to $25 \%$ in patients with poor LVEF. Unfortunately, our database does not capture left ventricular size or viability assessments. Thus, it is impossible to determine whether patients with poor preoperative left ventricular function had a stunned or hibernating myocardium versus those with an acute event in the setting of an established ischemic cardiomyopathy.

\section{CHF}

Similar to poor LVEF, CHF has been reported as one of the major predictors of operative mortality in patients requiring CABG. ${ }^{9,13} \mathrm{CHF}$ was present in $25 \%$ to $30 \%$ of the patient population, and the operative mortality in this group is $18.9 \%$ compared with $4.3 \%$ in patients without CHF $(P<.001)$.

Another outcome of interest in this study is the development of LCOS. Compared with operative mortality, LCOS is a more sensitive indicator of poor myocardial performance and has been associated with increased mortality and resource use. ${ }^{1-3}$ The prevalence of LCOS decreased from $26.5 \%$ to $18.6 \%$ over the years. However, the corresponding operative mortality increased from $22.1 \%$ to $35.3 \%$. Operative mortality in patients who had LCOS was $25.4 \%$ compared with $2.5 \%$ in patients who did not have LCOS. The independent predictors of LCOS are smaller body surface area, CHF, shock, MI, previous decade, and increased age.

\section{Limitations}

Our study is limited by the fact that it is retrospective in nature and reflects the experience of a single institution. Also, our outcomes are limited to in-hospital events, and follow-up outcomes on long-term survival are not available.

\section{CONCLUSIONS}

Although emergency CABG is viewed as a life-saving procedure, it continues to carry a high risk for morbidity and mortality, especially in patients with specific preoperative comorbidities. Despite a changing preoperative risk profile, the operative mortality of our emergency CABG has remained stable over the years. Continued 
improvements in the management of poor left ventricular function, heart failure, and the care of the elderly will likely result in reduced risks of emergency CABG.

\section{References}

1. Maganti M, Badiwala M, Sheikh A, Scully H, Feindel C, David TE, et al. Predictors of low cardiac output syndrome after isolated mitral valve surgery. J Thorac Cardiovasc Surg. 2010;140:790-6.

2. Maganti MD, Rao V, Borger MA, Ivanov J, David TE. Predictors of low cardiac output syndrome after isolated aortic valve surgery. Circulation. 2005;112(9 Suppl):I448-52.

3. Rao V, Ivanov J, Weisel RD, Ikonomidis JS, Christakis GT, David TE. Predictors of low cardiac output syndrome after coronary artery bypass. $J$ Thorac Cardiovasc Surg. 1996;112:38-51.

4. SAS Institute. SAS/STAT user's guide, version 8. Cary (NC): SAS Institute; 1988.

5. Hanley JA, McNeil BJ. The meaning and the use of area under a receiver operating characteristic (ROC) curve. Radiology. 1982;143:29-36.

6. Hanley JA, McNeil BJ. A method for comparing areas under receiver operating characteristic curves derived from the same cases. Radiology. 1983;148:839-43.

7. Hosmer DW, Lemeshow S. Applied logistic regression. New York: John Wiley and Sons; 1989.

8. Abramov D, Tamariz MG, Fremes SE, Guru V, Borger MA, Christakis GT, et al. Trends in coronary artery bypass surgery results: a recent, 9-year study. Ann Thorac Surg. 2000;70:84-90.
9. Christakis GT, Ivanov J, Weisel RD, Birnbaum PL, David TE, Salerno TA. The changing pattern of coronary artery bypass surgery. Circulation. 1989;80:1151-61.

10. Jones RH, Hannan EL, Hammermeister KE, Delong ER, O'Connor GT, Luepkar RV, et al. Identification of preoperative variables needed for risk adjustment of short-term mortality after coronary artery bypass graft surgery: the Working Group Panel on the Cooperative CABG Database Project. J Am Coll Cardiol. 1996;28:1478-87.

11. Davierwala PM, Maganti M, Yau TM. Decreasing significance of left ventricular dysfunction and reoperative surgery in predicting coronary artery bypass grafting-associated mortality: a twelve-year study. J Thorac Cardiovasc Surg. 2003; 126:1335-44.

12. Haan CK, O'Brien S, Edwards FH, Peterson ED, Ferguson TB. Trends in emergency coronary artery bypass grafting after percutaneous coronary intervention, 1994-2003. Ann Thorac Surg. 2006;81:1658-65.

13. Shahian DM, O'Brien SM, Filardo G, Ferraris VA, Haan CK, Rich JB, et al. Society of Thoracic Surgeons Quality Measurement Task Force. The Society of Thoracic Surgeons 2008 cardiac surgery risk models: part 1 -coronary artery bypass grafting surgery. Ann Thorac Surg. 2009 Jul;88(1 Suppl). S2-22.

14. Boylan MJ, Loop FD, Lytle BW, Taylor PC, Cosgrove DC. Have PTCA failures requiring emergent coronary bypass changed? ten year experience with 253 patients. Ann Thorac Surg. 1995;59:283-7.

15. Edwards FH, Carey JS, Grover Fl, Bero JW, Hartz RS. Impact of gender on coronary artery bypass operative mortality. Ann Thorac Surg. 1998;66:125-31.

16. Reinecke H, Fetsch T, Roeder N, Schmid C, Winter A, Ribbing M, et al. Emergency coronary bypass grafting after failed coronary angioplasty: what has changed in a decade? Ann Thorac Surg. 2000;70:1997-2003. 